\title{
WITTGENSTEIN: LA CONSCIÉNCIA DEL LIMITE - UNA CORVERSACIÓN COM Carla Carmona
}

[ WitTGENSTEIN: THE CONCIENSCIOUSNESS OF THE LIMIT - AN INTERVIEW WITH CARLA CARMONA ]

Carla Carmona é filósofa espanhola. Doutora em Filosofia pela
Universidade de Sevilha. É professora de Filosofia na Universidade de Sevilla. Especialista em estética, Filosofia da Linguagem, e Viena fin de siècle. Possui pesquisas de referência internacional sobre a estética no pensamento de Ludwig Wittgenstein. Publicou numerosos artigos sobre os pensamentos de Egon Schiele e Ludwig Wittgenstein. Tem desfrutado de numerosas estadias de investigação na Áustria, trabalhando com especialistas do contexto da Viena fin de siècle. Nos últimos anos, se dedicou ao estudo do pensamento estético e político de Peter Sloterdijk. Em 2014 publicou Tributação voluntária e responsabilidade cidadã. Vale a pena mencionar seus livros $A$ ideia pictórica de Egon Schiele: Um Ensaio sobre a lógica representacional (Edições Genueve, 2012), Tightrope do eterno: Na gramática alucinado Egon Schiele (Cliff, 2013), Egon Schiele: Writings 1909-1918 (a Micro, 2014), Ludwig Wittgenstein: La consciencia del limite (Biblioteca Discover filosofia, El País, 2015).

* Doutor em Filosofia. Professor do Centro Universitário Curitiba-UNICURITIBA. m@ilto: edimarbrigido@hotmail.com 
Edimar Brígido: Estimada profesora Carla Carmona, agradecemos la gentileza de concedernos esta entrevista, lo que contribuye a fortalecer el debate y los lazos filosóficos entre investigadores españoles y brasileños, de modo especial en lo que se refiere al pensamiento estético de Wittgenstein.

A propósito de la filosofía desarrollada por Ludwig Wittgenstein, estudios recientes han sugerido la existencia de un Wittgenstein más cercano a las discusiones antropológicas y estéticas, superando en alguna medida los debates tradicionalmente fundamentados alrededor de la lógica caboariana y del lenguaje. Nosotros nos referimos a un Wittgenstein más cercano al cotidiano, realidad en la que la vida realmente sucede en su dimensión más práctica, lo que podríamos denominar realismo empírico. ¿Está usted de acuerdo con esta nueva perspectiva? ¿Sería válido acercar a Wittgenstein de temas como la antropología y la estética?

Carla Carmona: Sí, estoy totalmente de acuerdo con esa manera de concebir el desarrollo de la filosofía de Wittgenstein. A mi me gusta pensar que la lógica inicial, pura, matemática, no es más que una parte ínfima de la lógica tardía de su última filosofía, animal, enraizada en los juegos de lenguaje, que a su vez hunden sus raíces en lo que podríamos llamar una forma de vida. ¿Por qué insistía tanto Wittgenstein en que lo único que cabía hacer era describir? Porque consideraba que no existe otro fundamento que el conjunto de prácticas circunscritas a una forma de vida, y estas solo pueden ser descritas, puesto que en el fondo no hay nada que explicar. En otras palabras: no queda otro principio lógico que no sea la lógica de la vida, en ese sentido, el único fundamento es antropológico. Digamos que toda su filosofía, su concepción filosófica, incluido su interés por el funcionamiento del lenguaje, da ese giro antropológico, al igual que su mirada es estética, lo que determinó su manera de trabajar.

Pero si tenemos en cuenta los diarios que escribió a la par que el Tractatus, y en general ese tipo de escritos más personales, que lo acompañaron durante toda su vida, nos encontramos con que Wittgenstein siempre estuvo preocupado por ese tipo de cuestiones. A veces cuando habla de sí mismo, incluso cuando lo está pasando verdaderamente mal, tenemos la impresión de que actúa como un antropólogo. También es importante recordar que Wittgenstein escribió sobre antropología, o más bien que criticó una práctica perniciosa de la antropología que se abandonaba a la inclinación de considerar tan limitados a los sujetos de estudio como para explicar comportamientos altamente complejos, como la práctica de la magia o determinados rituales, como resultado de la ignorancia e incluso la estupidez. Me refiero a las Observaciones a La Rama Dorada de Frazer, un librito maravilloso, indicativo de una mirada estético-antropológica envidiable.

Edimar Brígido: Entonces sería correcto considerar la vida de Wittgenstein, sus gestos, sus actos, sus reacciones, como la parte no escrita de su pensamiento filosófico?

Carla Carmona: En parte sí, en parte no. La vida de uno la constituyen 
muchas cosas y es imposible reunirla de manera coherente en una sola cosa, y si lo intentamos lo único que obtendremos será una narración mejor o peor contada. Lo cierto es que no soy dada a ese tipo de afirmaciones. Me parece un poco forzado el intentar encajar su vida en aquello que Wittgenstein dijo en relación al Tractatus a Ludwig von Ficker de que lo no escrito era tan importante como lo escrito en el libro. Creo que la filosofía de Wittgenstein puede iluminar gran parte de su biografía y viceversa, pero no me atrevería a decir que una es el revés de la otra, y no creo que biografía y vida tuvieran una sobre la otra la misma influencia en todo momento de su vida. Sé que habría quedado más atractivo responder que sí, y que Wittgenstein consideraba que lo no dicho era como el silencio, y que en la acción de alguna manera está la superación de la palabra y de la teoría, de tal manera que lo no dicho podría ser precisamente la vida vivida, que era además lo que consideraba fundamental, pero me temo que solo sería un bonito cuento.

Edimar Brígido: Sin embargo, en su vida, Wittgenstein no ahorró críticas al modelo estético que predominaba en su época. Mostró con su propia vida lo que pensaba acerca de las artes en general, decía con insistencia que deseaba haber vivido en otra cultura, en la que las artes estuvieran a la altura de la humanidad. Los artistas de diferentes áreas fueron destinatarios de sus consideraciones ácidas. ¿Sería correcto considerar a Wittgenstein un pesimista en materia de estética?

Carla Carmona: Me cuesta pensar a Wittgenstein como a un pesimista. Se ha hablado mucho de eso, y su pesimismo se ha relacionado con la influencia que Oswald Spengler y Otto Weininger tuvieron en él. No obstante, colocarle la etiqueta de pesimista me parecería reduccionista. Wittgenstein no se rendía. Estuvo luchando toda su vida, ya fuera contra los límites de su propia cabeza, digamos, en lo que respecta a su trabajo filosófico, como contra los límites de su alma, lo que él no dejaba de llamar sus pecados. No creo que alguien con esa inclinación a la autosuperación sea un pesimista. Además, enfrentándose a ambos, de alguna forma, pretendía cambiar la manera de pensar de sus posibles lectores. Su filosofía, lo dijo él mismo, era propaganda a favor de un tipo de pensamiento y en contra de otro.

Es cierto que fue muy crítico con lo que llamó el espíritu de su tiempo y que arremetía contra los estándares de las prácticas artísticas de su tiempo. Y probablemente en parte tuviera razón. No hay que olvidar que estamos hablando de la Viena de la Ringstrasse, por ejemplo, que tanto enfadó a Adolf Loos. El caso de la arquitectura es revelador, y el de la Ringstrasse en particular también. Wittgenstein pensaba que la arquitectura que se imponía a su alrededor no era auténtica. Pero desde su punto de vista esto era normal, pues no podía haber arquitectura genuina alli donde no existía cultura, donde en cambio todo giraba en torno a la idea de progreso y las individualidades más destacadas poco podian hacer aparte de intentar mantenerse a flote frente a los aparatos de fricción moralizante dirigidos en su contra. 
Esta falta de autenticidad está relacionada con la contraposición que establecida por Wittgenstein entre las posibilidades de un buen arquitecto en un buen periodo y las de un buen arquitecto en un mal periodo. Consideraba que el trabajo de un arquitecto está anclado en sus coordenadas espaciotemporales, que un contexto favorable potencia su capacidad creadora y que uno negativo apenas le permitirá mantenerse en pie, coartando enormemente su abanico de posibilidades. Cuando Wittgenstein hablaba de un buen arquitecto en un mal periodo pensaba en Eduard van der Nüll, quien en la segunda mitad del siglo XIX diseñó en estilo renacentista junto a August Sicard von Sicardsburg la Ópera Estatal de Viena. La pregunta a formular, según estas ideas, sería la siguiente: ¿qué podría haber hecho van der Nüll si por aquel entonces en Viena el corazón de la actividad arquitectónica lo constituía la construcción de la Ringstrasse? ¿Realmente podría haber hecho algo muy diferente a lo que hizo? ¿Qué hizo que Wittgenstein encontrara interesante el caso de un arquitecto aparentemente tradicional, profesor en la Academia desde 1844, de la cátedra de Perspectiva y Ornamentación? No nos olvidemos de que su edificio en el fondo despertó el malestar generalizado de una burguesía acostumbrada a la afectación. Parémonos en la ópera. Se trata de un edificio que imita el estilo del Renacimiento temprano y que no podía competir con el carácter monumental de su vecino en la acera de enfrente, el Heinrichshof (hecho añicos en la II Guerra Mundial y reemplazado por el actual Opernringhof). La creación de los dos arquitectos literalmente se salía del molde, y estaba muy lejos de ajustarse a lo que la gente estaba acostumbrada y esperaba ver. Pero no solo no satisfacía las expectativas del gusto generalizado, sino que, además, se empeñaba en hacer pensar a los transeúntes, los invitaba a la reflexión. ¿Acaso cabía comparar ese edificio relativamente modesto con su alrededor? ¿Estaba a la altura de lo demás? Pero ¿entonces lo demás estaba a su altura? Este edificio de la ópera incitaba a mirar los edificios vecinos desde sus estándares particulares. ¿Por qué habría que recargar tanto las superficies? ¿Acaso era necesario? Entonces ¿cómo es que la ópera no participaba de esa manera de ornamentar? Pero el ciudadano no quería reflexionar. Además, la altura de la calle resultó ser mayor de lo previsto y la reacción general fue considerar que el edificio parecía estar hundido. Esto último se comparó con la entonces reciente batalla de Königgrätz, que resultó ser un auténtico desastre para el Imperio, y se extendió el uso de imágenes perversas para ridiculizarlo. Este incidente, que tuvo tal impacto en van der Nüll que pudo haberlo conducido al suicidio, no quita que este, en el fondo, fuera un arquitecto conservador. Después de todo, a pesar de las fricciones que causó el carácter despojada de la renacentista fachada de la ópera, fue una figura de transición, que sirvió de puente entre Gottfriend Semper y Otto Wagner y, en consecuencia, con Loos, pero el eclecticismo en el edificio de la ópera traicionaba el espíritu que inflamaba el trabajo de este último, a quien Wittgenstein reconoció entre los pocos que habrían tenido un impacto profundo en lo que denominó su método de clarificación. 
También es cierto que Wittgenstein desconocía mucho de lo que pasaba a su alrededor, a pesar de que perteneciera a una familia tan entusiasta, curiosamente, por las artes entonces contemporáneas. Y esto tiene que ver con el gusto conservador que tenía Wittgenstein. Reconoció en varias ocasiones que ciertas cosas que si habrían estado a la altura le resultaban incomprensibles, a pesar de que reconocía que en ellas habia algo que se le escapaba, como en la poesía de Rainer Maria Rilke, Georg Trakl o Ludwig Uhland. Apenas prestó atención a la música que era abucheada en los teatros vieneses por unos oídos aburguesados que no querían abrir los ojos a las posibilidades, tanto éticas como formales, de la dodecafonía, por ejemplo. Tampoco intentó distinguir las edulcoradas mujeres de Gustav Klimt de las inquietantes figuras de Egon Schiele.

Edimar Brígido: Me parece que Wittgenstein fue un esteta que se negó a desarrollar una teoría estética. ¿Estaría usted de acuerdo?

Carla Carmona: Mi amigo el filósofo Isidoro Reguera escribió una vez que toda la filosofía de Wittgenstein tiene un carácter estético. Estoy totalmente de acuerdo con esa afirmación. Es importante tener en cuenta que de alguna manera Wittgenstein se mantuvo fiel a aquello que escribió en el prólogo al Tractatus, que lo contenido en el libro era tan importante como la forma en la que esas ideas estaban expresadas. Que Wittgenstein no llegara a publicar ninguna otra obra filosófica después del Tractatus se debe en parte a que nunca estuvo satisfecho con la forma que había logrado en sus manuscritos.

De que esto para él era fundamental da fe su forma de trabajar: el que rescribiera una y otra vez sus parágrafos. Empezaba escribiendo observaciones en pequeñas libretas. De ellas seleccionaba las que consideraba mejores y las pasaba a un volumen manuscrito de mayor tamaño. Acto seguido, volvía a preparar una selección que encargaba mecanografiar. Pero eso no era todo. Todavía insatisfecho con el resultado de esas cribas, continuaba seleccionando y reordenando el material hasta abandonar la idea de concluir su trabajo. Mientras trabajaba en las Investigaciones, acumuló abundante material adicional que posteriormente fue publicado de manera independiente, si bien originalmente lo concibió con la idea de utilizarlo para la que consideraba la obra filosófica de su vida. Ese es el caso de Observaciones sobre los fundamentos de las matemáticas. Esta no es la única obra que Wittgenstein escribió casi sin querer. Piénsese en los Últimos escritos sobre Filosofía de la Psicología. En concreto, el segundo volumen, sobre lo interno y lo externo, sea probablemente el trabajo de Wittgenstein que más me interese.

Creo que a Wittgenstein le hubiera desagradado sobremanera ser considerado un esteta, y de hecho él nunca se ocupó de las cosas a la manera de los estetas. Más que un esteta, fue un filósofo total, y uno incendiario, por eso se comparaba con quien incendió la biblioteca de Alejandría. Lo que poseía era una mirada estética extraordinaria, con la distancia que eso 
supone. Desde luego, no tenía una teoría estética, como usted sabe, Wittgenstein despreciaba la teoría. Cuando se ocupó de cuestiones de estética filosóficamente lo hizo de la misma manera con la que se ocupaba de cualquier otro asunto filosófico, demoliendo falsos ídolos. En el caso de la

$\overline{182}$ belleza, por ejemplo, estaba enfrascado en convencer al lector para que dejara de preguntarse por la belleza con mayúsculas, e incluso por la belleza en general. La pregunta '¿qué es la belleza?' tenía que ser reemplazada por ‘¿ómo se usa la palabra bello en ese contexto?'. No existe la belleza, sino usos de una palabra, y usos infinitos, por eso la necesidad de lograr una visión sinóptica. ¿Qué maravilloso concepto el de Übersichtlichkeit”!

Edimar Brígido: Pero entonces, desde el punto de vista filosófico, ¿cuál es la importancia de la estética en el pensamiento de Wittgenstein?

Carla Carmona: Creo que la estética juega un papel central en la filosofía de Wittgenstein, en especial lo que él entendía por estética y practicaba como estética. En primer lugar, está en estrecha relación con la concepción del lenguaje que mantuvo en obras tardías, como en Sobre la certeza, pues la estética está muy cerca de lo que Wittgenstein entendía por animalidad. ¿Recuerda ese parágrafo de Sobre la certeza en el que Wittgenstein defiende que el lenguaje no es fruto del razonamiento, sino de un estado más primitivo? Es el 475, y dice así: "Quiero considerar al ser humano aquí como un animal; como un ser primitivo al que se le atribuye instinto, pero no razonamiento. Como una criatura en estado primitivo. No tenemos que avergonzarnos de una lógica que es suficiente para un modo primitivo de comunicación. El lenguaje no ha surgido de un razonamiento."

Aristóteles ya había defendido que el hombre es un animal que habla. Sin embargo, el estagirita parecía hacerlo con la idea de diferenciar al ser humano del animal. El propósito de Wittgenstein es el contrario: retrotraer el lenguaje a la naturaleza animal del hombre, a lo que comparte con las otras bestias, por decirlo de algún modo. Somos un tipo de animal especial al que la lógica del lenguaje se le tiene que inculcar. De ahi que Wittgenstein sea conocido por comparar el entrenamiento necesario para la formación de conceptos, el aprendizaje "humano", con el adiestramiento. Usar el lenguaje sería por encima de todo una cuestión de responder de forma adecuada.

Hemos de viajar a este contexto originario para entender el carácter gestual que Wittgenstein atribuía al lenguaje. No es gratuito que decidiera estudiar formas primitivas de lenguaje para alcanzar a explicar la complejidad del lenguaje humano. Ése es el germen del concepto de "juego de lenguaje", una especie de mini-lenguaje que Wittgenstein define como "objeto de comparación", un conjunto de prácticas estrictamente limitado que sirve como patrón de medida con respecto al cual comparar determinados aspectos del lenguaje con vistas a su comprensión. La naturaleza del lenguaje también está contenida en el gesto. Es conocido el demoledor 
impacto que el perspicaz gesto de Piero Sraffa tuvo sobre la teoría pictórica del lenguaje defendida en el Tractatus. La palabra no es portadora de un significado perenne. Su sentido le viene dado por el contexto especifico que la enmarca, por la ocasión en la que tiene lugar. Adiós a las esencias: el concepto de uso entra en escena.

El carácter gestual del lenguaje se pone particularmente de manifiesto en la apreciación estética. Pongamos atención a cómo aprendemos a usar una palabra como "bello". Es enseñada como una interjección. Probablemente la palabra fuera acompañada de gestos y expresiones faciales excesivas, con tanta carga de significado como ella. De hecho, Wittgenstein insiste en que palabra y gesto pueden entenderse como expresiones equivalentes. Piensen en el ejemplo del silencio, cuando este se da como un gesto. Esa relación de equivalencia entre gesto y palabra explica que en ocasiones tengamos la sensación de que el silencio puede ser la mejor alternativa a una palabra, que llegar a comunicar incluso más que ésta. Podríamos decir que nuestras reacciones estéticas son fundamentalmente gestuales, literalmente, gestos verbales.

Al mismo tiempo, la estética es fundamental para la filosofía porque su principal tarea, desde el punto de vista de Wittgenstein, es describir, al menos el de una de sus dimensiones fundamentales, la de la crítica de arte. Cuando se piensa en estética wittgensteiniana se tiende a reducirla a simple filosofía del lenguaje de nuestras expresiones estéticas, pero lo cierto es que Wittgenstein indicó otras posibilidades, otros posibles caminos para la estética, y uno de ellas, y muy claro, era el de la crítica de arte. Yo lo he estudiado en un trabajo sobre las correspondencias entre la filosofía de Wittgenstein y la crítica de arte de Clement Greenberg. ¿Qué es lo que hace el critico de arte? (¿O qué es lo que esperaríamos que el crítico de arte hiciera más a menudo en los tiempos que corren?) Describir. Por ello Wittgenstein pensaba que el filósofo tenía mucho que aprender de la estética, en particular, del crítico de arte, de quien admiraba su capacidad para establecer relaciones poniendo una cosa junto a otra y para llamar la atención sobre rasgos concretos, hasta el punto de lograr cambiar lo que el espectador ve en las obras de arte, en otras palabras, su manera de ver las cosas, su manera de mirar.

$Y$ quien dice estética, dice arte, pues Wittgenstein no diferenciaba realmente entre lo estético y lo artístico, y mucho de lo que decía de la estética, si no todo, se extiende al arte y viceversa. Volviendo al carácter gestual del lenguaje, cabe recordar esa máxima wittgensteiniana de que la arquitectura es un gesto. Y al igual que del crítico de arte, el filósofo tenía mucho que aprender del arquitecto, pues consideraba que el trabajo en arquitectura, después de todo, era como trabajar sobre uno mismo, sobre la propia concepción de las cosas. Y también nos invitó a aprender del dibujante, y comparó su tarea filosófica con la de un dibujante que se acercara a su objetivo desde todos los ángulos posibles. Pero pasemos a la siguiente 
pregunta.

Edimar Brígido: La profesora Carla, para finalizar, podría hablarnos un poco acerca de la obra "Ludwig Wittgenstein: La consciencia del limite"?

184 Carla Carmona: La consciencia del límite es una obra que pretende acercar el pensamiento de Wittgenstein a cualquier persona interesada,

¿ independientemente de que tenga formación filosófica o no. No por ello, sin embargo, se trata de un libro de divulgación, puesto que las cuestiones y problemas filosóficos que interesaron a Wittgenstein se estudian en profundidad. Traté de dar un enfoque completo del pensamiento de Wittgenstein, que recogiera tanto los intereses lógicos que lo llevaron a Cambridge, a trabajar junto a Bertrand Russell, o el giro antropológico que dio su filosofia del lenguaje, como las preocupaciones que compartía con aquellos modernos críticos que por entonces coincidieron en Viena, me refiero a autores como Karl Kraus, Adolf Loos u Otto Weininger. Coincido con Allan Janik y Stephen Toulmin en que no se puede comprender la filosofía de Wittgenstein, y menos aún su cosmovisión, si uno no tiene en cuenta el universo de sentido que le procuraba su procedencia vienesa, y la pertenencia a una familia tan involucrada en las artes y el pensamiento arropadas en aquella ciudad como la suya.

Tras dar cuenta de sus continuas idas y venidas entre Cambridge y Viena, dedico un capítulo a explicar los puntos fundamentales de su primera obra, el Tractatus logico-philosophicus, dedicando especial atención a las relaciones entre la lógica y la ética, aclarando por qué Wittgenstein pensada que no se podía ser un lógico si no se era previamente un hombre (éticamente hablando). En el capítulo siguiente, me ocupo de las Investigaciones filosóficas, una de las obras fundamentales de la filosofía de todos los tiempos. Mi propósito es acercar al lector a los problemas fundamentales tratados allí, como las ideas de que el significado de una palabra está en cómo es usada, de que no existe algo así como un lenguaje privado o de que lo único que puede hacer la filosofía es describir, y a algunos conceptos fundamentales, muy útiles para comprender cosas de la vida cotidiana, como el de ver cómo.

En el cuarto capítulo me centro en lo que hizo entre el Tractatus y las Investigaciones y después de las Investigaciones, de esa forma establezco paralelismos entre su experiencia como arquitecto y el carácter animal, gestual, que atribuyó al lenguaje en su última filosofía, como en Sobre la certeza. Asimismo, en relación a esta obra fundamental, dedico un capítulo a explicar las reflexiones de Wittgenstein acerca de los límites de la duda. La idea de Wittgenstein de que existen una serie de creencias especiales, las certezas, de las que no cabe dudar, puesto que forman parte de nuestro marco de referencia, es esencial para comprender la insistencia de Wittgenstein en la necesidad de frenar el escepticismo. Finalmente, el libro termina con una pequeña reflexión acerca de los posibles usos contemporáneos de la filosofía 
de Wittgenstein.

Edimar Brígido: ¿Cuáles serían esos usos?

Carla Carmona: Como usted sabe, Wittgenstein ha calado muy profundamente en el imaginario de disciplinas extremamente variadas, desde la lógica hasta el arte, pasando por el feminismo. Los usos que se han hecho de su filosofía son tan variados como sus propias observaciones filosóficas. Si dejamos a un lado las disciplinas obvias, como la filosofía del lenguaje o la lógica, su filosofía ha dejado una huella ineludible en la filosofía de la ciencia, la antropología, la filosofía de la mente, la estética, en particular la filosofía de la música, la ética, la filosofía de la religión o la filosofía política. Esta influencia a la vez tan diversa e intensa se debe en parte a que los conceptos sobre los que pivota su filosofía son muy poderosos y tienen una potencia extraordinaria.

Eso explica que el concepto de juego de lenguaje haya sido explorado por arquitectos, artistas plásticos, estetas, críticos de arte, antropólogos o estudiosos de la religión, pues da cabida a reflexionar acerca de todas las prácticas humanas, incluidas nuestras formas artísticas y las expresiones religiosas, como si estuvieran constituidas por juegos de lenguaje concretos, fruto de las exigencias de las formas de vida que los circunscriben. El concepto de juego de lenguaje puede ser clave para comprender en su complejidad el debate acerca de la autonomía del arte. ¿El arte es algo autónomo, independiente de la vida, un juego de lenguaje que puede apreciarse en si mismo, sin necesidad de atender a nada más, o por el contrario bebe de la forma de vida a la que pertenece, y cuanto más conozcamos de las prácticas coetáneas a ese juego de lenguaje, y del trasfondo en que uno y otras están inscritos, más profunda será nuestra apreciación? En este sentido, la observación que hace Wittgenstein en las Lecciones sobre estética de que para comprender nuestras expresiones estéticas es necesario comprender toda una forma de vida puede extenderse a la apreciación de una obra de arte. No obstante, el concepto de juego de lenguaje también apunta a una cierta objetividad, no tajante ni dogmática, sino relajada, en lo que respecta a la apreciación de una obra de arte en cuestión, que vendría dada por la propia obra, y por el trasfondo en el que esta está arraigada, del cual es inseparable.

El concepto de juego de lenguaje también ha desempeñado un papel fundamental en los debates acerca del relativismo cultural y permite pensarlo desde perspectivas muy interesantes. ¿Acaso cada cultura tiene su propio juego de lenguaje, con reglas que le son inherentes y cuyo ámbito de validez no trasciende los límites del juego, es decir, esas reglas concretas, culturales? ¿O podemos hablar de un jugar humano universal, más esencial, que de alguna forma se viera permeado por las diferentes formas culturales humanas? En ese sentido, y volviendo sobre el concepto de certeza, también cabe preguntar lo siguiente: ¿existiría un conjunto de certezas humanas 
universales, o estas certezas constituirian marcos de referencia particulares, es decir culturales? Otra pregunta que me parece fundamental para el mundo globalizado en el que vivimos en la actualidad es ¿cómo podemos adiestrarnos en los juegos culturales ajenos? Imparto docencia en un Grado de Estudios en Asia Oriental, y precisamente estos días estoy explorando con mis alumnos el uso del concepto de juego de lenguaje en el contexto del diálogo intercultural. Es hermoso comprobar que es una herramienta que los jóvenes de hoy en día entienden bien, que tiene sentido para ellos y pueden aplicar con facilidad. Siempre he pensado que Wittgenstein puede resultar muy útil para acabar con el anti-antirrelativismo, por recuperar el término de Clifford Geertz.

Incluso la distinción tractariana entre el decir y el mostrar ha sido aplicada al contexto de la memoria histórica con vistas a dilucidar si determinados sucesos desmedidos son realmente irrepresentables, tan y como se ha afirmado en determinadas ocasiones, o por el contrario pueden ser representados de forma no explícita, como haria por ejemplo el film Shoah de Claude Lanzmann. Y han sido muchos artistas los que se han apropiado ideas tanto de su primera filosofía como de la tardía. Por ejemplo, muchos artistas han reaccionado a la propuesta antiesencialista wittgensteiniana, la que, por otro lado, ha marcado literalmente el debate contemporáneo acerca de la posible definición del arte.

Estos son solo algunos usos. Por finalizar, me gustaría también llamar la atención sobre el hecho de que el pensamiento feminista también ha sabido sacarle partido a la filosofia de Wittgenstein, reflexionando, entre otras cosas, acerca de cómo determinadas prácticas transgresoras pueden animar a actuar de maneras alternativas a las habituales a quien las observa como un espectador. Con este ejemplo vemos que en el contexto del feminismo se hace un uso político de Wittgenstein que busca promover una conexión directa entre el modo de ver las cosas y el modo de actuar, que es, por otro lado, algo en lo que Wittgenstein creía firmemente. Esa reflexión acerca de las prácticas transgresoras abierta desde la filosofía de Wittgenstein casa a la perfección con un aspecto fundamental de la propuesta filosófica de Judith Butler, a saber, su idea de que puesto que no podemos salirnos del reglamento del género, puesto que hemos de enfrentarnos a él desde dentro, lo único que cabe es la parodia. Esta idea de transgredir la norma desde el interior, por otro lado, también podría enriquecerse con la precisión con la que el primer Wittgenstein expresó que solo cabía enfrentarse a los límites del lenguaje desde dentro. Más obvio es que el carácter anti-esencialista de la filosofía madura de Wittgenstein puede ser utilizada para fundamentar la convicción butleriana de que no existe algo así como lo que llamamos alegremente 'mujer'. 